\title{
The latent factors of depression from the short forms of the CES-D are consistent, reliable and valid in community-living older adults
}

\author{
A.M. O'Halloran a,*, R.A. Kenny ${ }^{\text {a,b }}$, B.L. King-Kallimanis ${ }^{\text {a }}$ \\ ${ }^{a}$ The Irish Longitudinal Study on Ageing (TILDA), Department of Medical Gerontology, Trinity College, Dublin 2, Ireland \\ ${ }^{\mathrm{b}}$ Mercer's Institute for Successful Ageing (MISA), St. James's Hospital, Dublin 8, Ireland
}

A R T I C L E I N F O

\section{Article history:}

Received 29 August 2013

Accepted 14 December 2013

Available online $\mathrm{xxx}$

\section{Keywords:}

Depression

CES-D

Positive affect

Older adults

Disability

Perceived stress

\begin{abstract}
A B S T R A C T
Background: Depression is an important public health outcome in the older adult population. It is associated with declining physical and psychological well-being and increasing healthcare utilisation. The Center for Epidemiological Studies Depression Scale (CES-D) although widely accepted as a screening tool for depressive symptoms in older adults, can be long and exhaustive as part of a comprehensive geriatric assessment.

Aim: We investigated the consistency, reliability and validity of the original and three short formats of the CES-D.

Methods: Six thousand six hundred and thirty-seven community-living adults, aged $\geq 50$ years from The Irish Longitudinal Study on Ageing (TILDA), completed the 20-item CES-D. Confirmatory factor analysis determined the factor structures of the 20-, 10- and two 8-item formats of the CES-D. Latent factors from each format were validated against disability and perceived stress, particularly the Positive Affect factor. Analysis was also performed in a subset aged $65+$ years.

Results: All formats of the CES-D displayed good internally consistency (0.87-0.72) and good model fit for the expected four- and three-factor structures of the CES-D. Latent factors from all formats were representative of each other and the Positive Affect factor was negatively correlated with disability and perceived stress on all CES-D formats.

Conclusion: Short forms of the CES-D are consistent, reliable and valid for use in the older adult population (50+ or 65+ years), where avoiding long assessments and response fatigue is warranted. These formats may be used to measure Positive Affect, an important construct related to physical health, resilience and psychological well-being in later life.
\end{abstract}

(C) 2014 Published by Elsevier Masson SAS.

\section{Introduction}

Depression, an important public health outcome in the older adult population, is associated with declining physical and psychosocial well-being and increasing health service utilisation. All of which become more prevalent as we age $[1,2]$. The Center for Epidemiological Studies Depression Scale (CES-D), a widely accepted screening tool for assessing depressive symptoms in the older population, has been shown to have good psychometric properties and strong correlations with clinically diagnosed depression $[3,4]$.

The 20-item CES-D is most often represented by the four-factor structure (Depressed Affect, Positive Affect, Somatic and Retarded Activity, and Interpersonal Problems), originally proposed by Radloff (1977) using principal components analysis (PCA). Subsequent

\footnotetext{
* Corresponding author. TILDA, Department of Medical Gerontology, Lincoln Gate, Trinity College, Dublin 2, Ireland. Tel.: +353 8962334.

E-mail address: aiohallo@tcd.ie (A.M. O'Halloran).
}

evaluations using different factor analysis techniques have demonstrated similar results across older age groups $[5,6]$.

However, not all studies have replicated the four-factor structure. A three-factor structure, combining Depressed/and Somatic Affect, provided the best fit using confirmatory factor analysis (CFA) in two female samples of low-income and MexicanAmerican women, respectively [7,8]. Meanwhile, PCA of the Dutch version of the CES-D across cancer patients and a nonclinical group, indicated the best model fit was a two-factor solution (Depressed Affect and Positive Affect) [9]. They concluded that there was weak support for the validity of the Positive Affect items as a measure of depression. This is contrary to previous research using the English version of the CES-D, which demonstrated a four-factor structure and supported the validity of the Positive Affect items [10,11].

Efforts have been made to derive more parsimonious formats of the CES-D, to facilitate administration to older adults. Both 11- and 10 -item formats have shown good reliability and validity $[12,13]$. An 8-item format was also formulated to screen for depressive symptoms in large cohorts of older adults, e.g. Health and 
Retirement Study [14] and the European Social Survey [15]. Item reduction has yielded some inconsistency regarding the factor structure of the shorter forms of the CES-D in older cohorts, with two- and three-factor structures reported, mainly in Asian populations [16,17]. Despite this, Positive Affect as measured by the CES-D, has been inversely correlated with Negative Affect, activities and instrumental activities of daily living (I/ADL), and poor psychological health in older adults [18-20].

Our aim was to investigate the structure of the long (20-item) and short (10- and 8-item) forms of the CES-D in a large, representative, community-living sample of adults aged 50 years and over, and in the subset aged 65 years and over. Upon identifying satisfactory measurement models, our objective was to validate these latent factors using measures of physical disability and perceived stress.

\section{Methods}

\subsection{Study design}

At baseline, The Irish Longitudinal Study on Ageing (TILDA) included 8175 participants representative of the communityliving population aged 50 and over in Ireland. The sampling procedure and the home interview have been described in detail previously [21]. Measures specific to the current analysis are described below.

\subsection{Measurements}

The items and scoring of the CES-D are provided in Appendix 1 $[4,12,15]$. Participants completed the CES-D once and responded to the 20 items by indicating how often they had felt that way in the past week: $0=$ rarely or none of the time ( $\leq 1$ day), $1=$ some or a little of the time (1-2 days), 2 = a moderate amount of the time (34 days), and $3=$ most of the time (5-7 days).

A binary-response version of the CES-D8 was generated by converting the participant responses "rarely or none of the time" and "some or a little of the time" equal to "No" and "a moderate amount of the time" and "most of the time" equal to "Yes" [12,14]. The Positive Affect items were reverse scored for all versions of the CES-D.

A 6-item version of the ADL scale was used to assess one's ability to perform daily self-care activities (walking, dressing, bathing, eating, getting in and out of bed and using the toilet), and is a measure of functional status and/or disability. Scores were dichotomized to represent presence/absence of any ADL disability.

A 6-item version of the IADL scale measured an individual's ability to live independently in the community. IADLs assess respondents' ability to perform certain activities, i.e. manage money, shop, use the telephone, housekeep, prepare meals and take medications correctly. Scores were dichotomized to represent presence/absence of any ADL disability.

Participants completed the Perceived Stress Scale (PSS-4) by indicating how often they had experienced four situations in the last month: "felt that you were unable to control the important things in your life", "felt confident about your ability to handle your personal problems", "felt that things were going your way" and "felt difficulties were piling up so high that you could not overcome them" [22]. Responses ranged from: $1=$ never, through $5=$ very often. The two positively stated items were reverse scored. Higher scores signify greater levels of perceived stress (range 0-16).

\subsection{Analysis}

All analyses were performed using Mplus (v6). We used CFA to test the factor structures of the long and short forms of the CES-D.
As the items are ordinal (or binary), we used the weighted least square means and variance adjusted (WLSMV) estimator to estimate model parameters.

Radloff's original four-factor structure was tested for the 20and 10-item CES-D formats. A three-factor structure (Depressed Affect, Positive Affect, and Somatic and Retarded Activity) was tested for the 8-item formats, because the two Interpersonal Problems items are not present in these formats. We estimated the reliability of all formats using Cronbach's alpha $(\alpha)$ coefficient. Overall model fit was assessed by adjusted Chi-square test, where a non-significant value was indicative of good fit. We also considered approximate fit indices: root mean square error of approximation (RMSEA) values of $<0.08$ and $<0.05$ indicated satisfactory and close model fit, respectively and weighted root mean square residual (WRMR), where $\approx 1.0$ indicates satisfactory fit [23].

Changes to the model were guided by the modification indices, the expected parameter changes (EPC) and substantive interpretation of the misspecification. The modification index provides an estimate of the expected change in the adjusted Chi-square value if the parameter were estimated and the EPC provides an estimate of the size of the parameter were it estimated. Due to multiple testing, we only consider the modification index to be significant after a Boferroni correction, in conjunction with an EPC greater than a small effect size and substantive interpretability [24]. If model changes were required, the new model (alternative) was compared to the previous model (null) using the DIFTEST procedure. This tests the difference in the overall model fit between the null and alternative models [25].

Using structural equation modelling, the CFA model was extended, allowing a simultaneous investigation of the effects of IADLs, ADLs and Perceived Stress on the latent factors of depression while controlling for age and sex. Regression coefficients for each model were examined to investigate whether the different forms of the CES-D had an effect on the results and conclusions.

Analyses were performed for the total cohort aged 50+ years and for a subset aged $65+$ years.

\section{Results}

\subsection{Characteristics of the sample}

Of the 8175 participants aged $\geq 50$ years recruited to TILDA, 8044 (98.4\%) had no missing data on the 20-item CES-D 20. A selfadministered questionnaire was completed by 6800 of these participants and included the PSS-4 and of these, 6542 participants had complete data for the PSS-4, ADLs and IADLs. This comprised the full dataset. Appendix 2 provides an overview of the participant characteristics.

\subsection{Factor structure of the four CES-D scale formats in the 50+ age group}

Data was imputed for an additional 95 participants with one missing item from the CES-D using Mplus, bringing the sample size to 6637.

Overall reliability estimates were $0.87,0.78$ and 0.72 for the 20 -, 10 - and 8-item formats, respectively. The latent factors also displayed good reliability with the exception of the Interpersonal Problems factor from the 20 -item format (Table 1 ).

Initially, the four-factor structure had unsatisfactory fit for the long form. However, with the inclusion of four residual covariances, the model had satisfactory fit $\left(\chi^{2}(160)=764.23, P<0.001\right.$, RMSEA $=0.024,90 \% \mathrm{CI}=0.022-0.024$, WRMR $=1.30$ ) (Fig. 1a). Residual covariances were between the items "sad" and "crying spells", "sad" and "lonely", "everything was an effort" and "not get going" and "I felt lonely" and "crying spells". For the 10-item 
Table 1

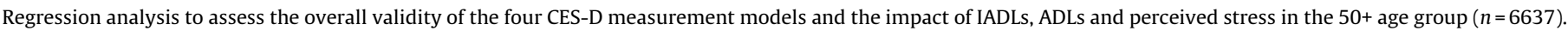

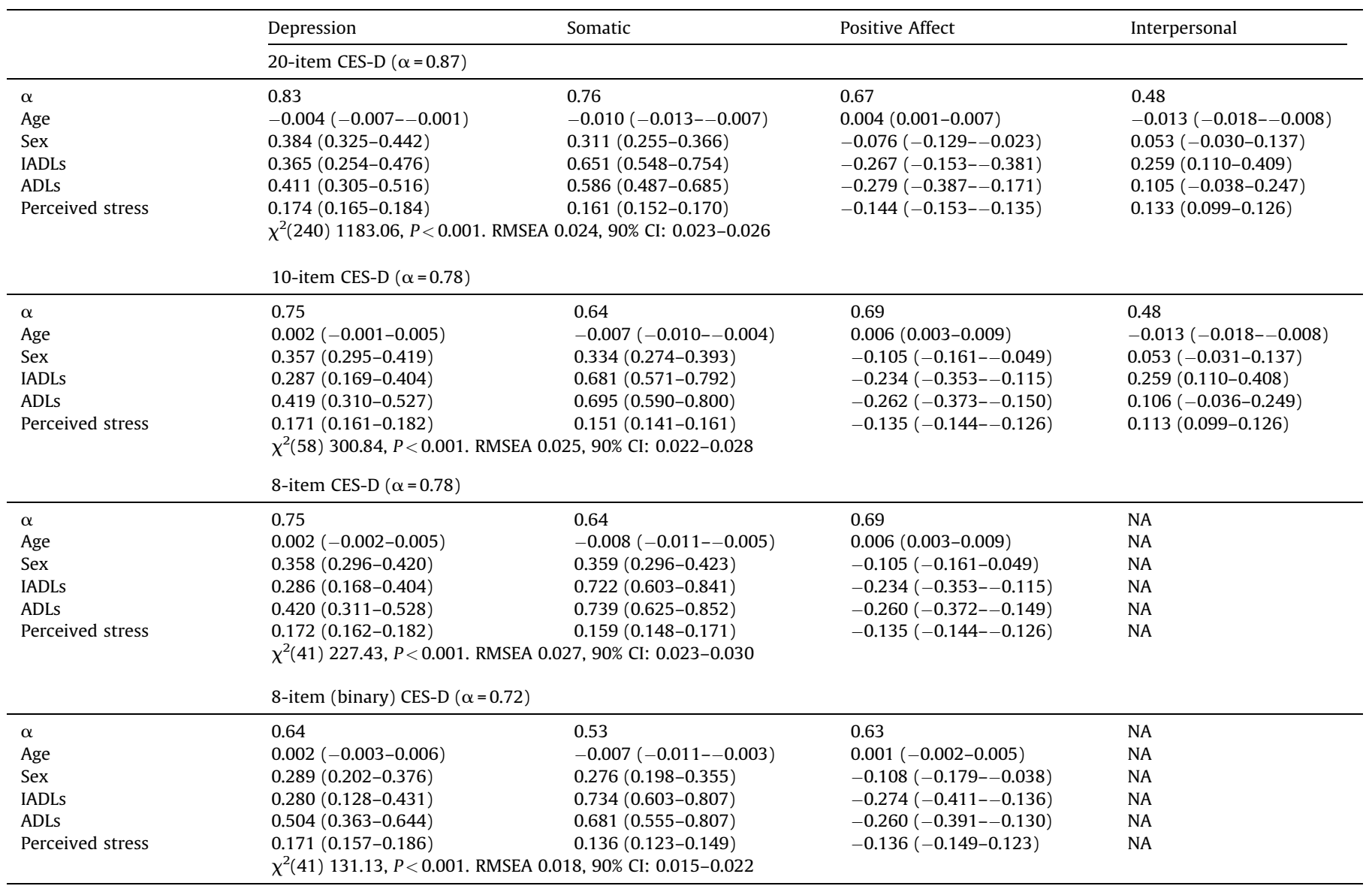

Values reported are regression coefficients $(\beta)$ with 95\% confidence intervals (95\% CI); $\alpha$ : Cronbach's alpha coefficient.

version, a four-factor structure was identified with satisfactory overall model fit $\left(\chi^{2}(28)=123.70, P<0.001\right.$, RMSEA $=0.023,90 \%$ $\mathrm{CI}=0.019-0.027$, WRMR $=0.87$ ) with the inclusion of one residual covariance between "sad" and "lonely". Satisfactory model fit was achieved for the 3-factor 8-item CES-D with residual covariances between "sad" and "lonely", and "everything was an effort" and "not get going" $\left(\chi^{2}(15)=50.37, P<0.001\right.$, RMSEA $=0.019,90 \%$ $\mathrm{CI}=0.013-0.025, \mathrm{WRMR}=0.63)$. Finally, the 8-item binary version required one residual covariance between "sad" and "lonely" to achieve satisfactory model fit $\left(\chi^{2}(16)=26.26, \quad P=0.054\right.$, RMSEA $=0.010,90 \% \mathrm{CI}=0.000-0.016, \mathrm{WRMR}=0.63)$.

3.3. Validity of the latent factors of depression from four CES-D scale formats in the 50+ age group

Measurement models were extended to include IADLs, ADLs and Perceived Stress as exogenous variables (Table 1). These variables were regressed on the latent factors for each of the four models. Overall, we found that the effects of disability and perceived stress on Depressed Affect, Somatic Affect, Interpersonal (20- and 10-item formats) and Positive Affect were very similar regardless of the number of items used to represent the factor. We found that participants with greater stress or disabilities in ADLs or ADLs reported higher Depressed Affect and Somatic Affect, but lower Positive Affect. The gender coefficients were somewhat lower on the binary 8-item format and the ADL coefficients on Depressed Affect were also lower for all three short forms. Finally, the IADL coefficients on Somatic Affect were higher on the short forms. However, all relationships remained significant with the same direction of effect.

\subsection{Factor structure of the four CES-D scale formats in the $65+$ age group}

Data was imputed for an additional 51 participants with one missing item from the CES-D using Mplus, bringing the sample size to 2769 in the $65+$ age group.

Overall reliability estimates were slightly lower than in the total cohort at $0.83,0.76$ and 0.67 for the 20-, 10- and 8-item formats, respectively. The latent factors for Depressed Affect and Positive Affect again displayed good reliability on all formats, although Somatic Affect displayed poor reliability on the binary 8item format. Again the Interpersonal Problems factor from the 20and 10-item formats displayed poor reliability (Table 2).

Similar to the overall cohort, the four-factor structure had satisfactory fit for the long form, with the inclusion of two of the four residual covariances observed in the 50+ age group $\left(\chi^{2}(162)=329.56, \quad P<0.001, \quad\right.$ RMSEA $=0.019, \quad 90 \% \quad C I=0.016-$ 0.022 , WRMR $=0.92$ ) (Fig. 1b). Residual covariances were between the items "sad" and "crying spells" and "sad" and "lonely". The same four and three-factor structures were observed for the 10and both 8-item versions, with the inclusion of the same residual covariance between "sad" and "lonely" in the 65+ age group, however, the covariance between "everything was an effort" and "not get going" seen in the 8-item version was not included. Model fit was satisfactory $\left(\chi^{2}(28)=47.22, P=0.013\right.$, RMSEA $=0.016,90 \%$ 

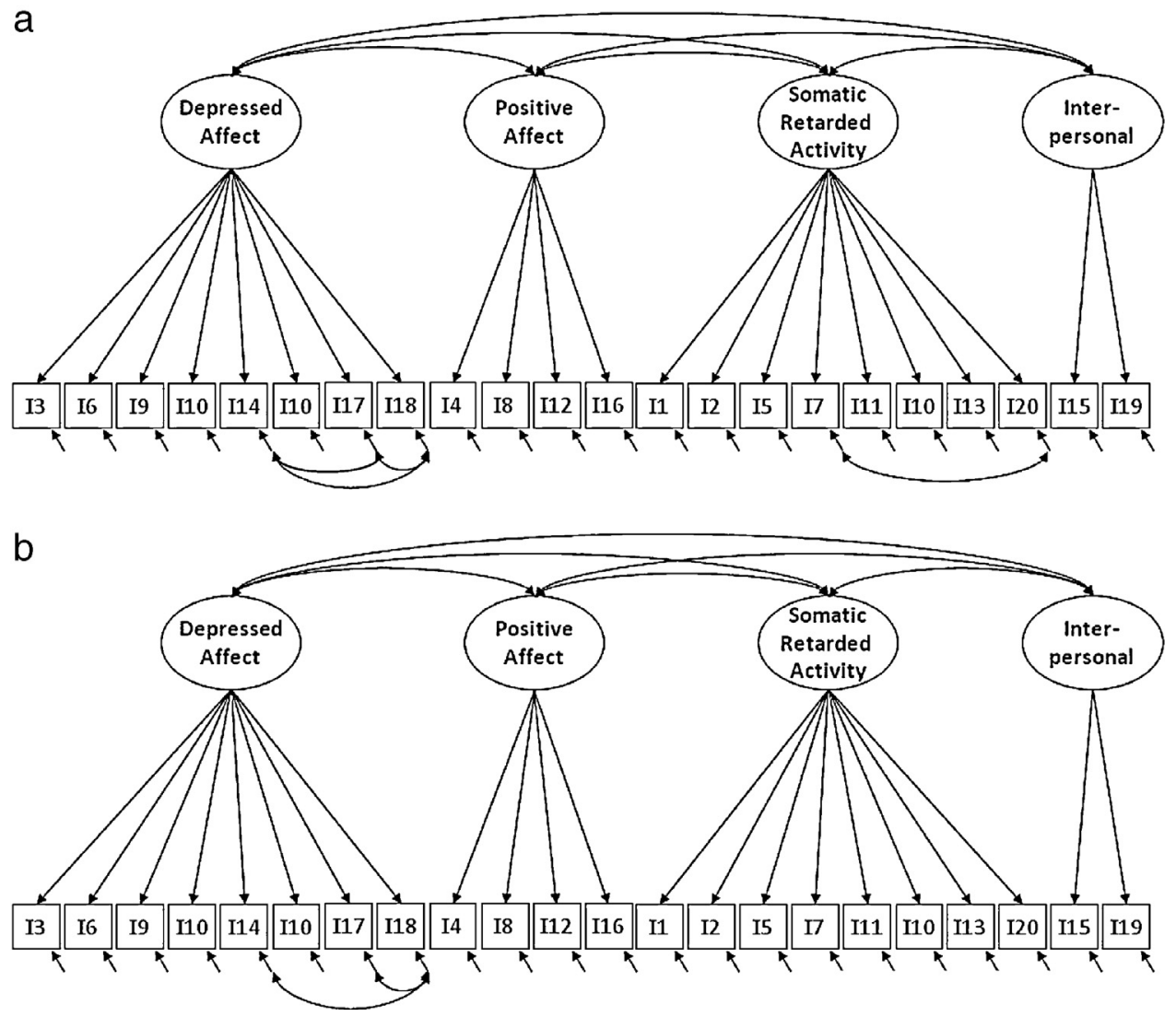

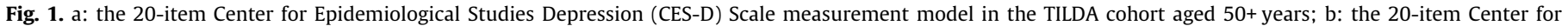
Epidemiological Studies Depression (CES-D) Scale measurement model in the TILDA cohort aged 65+ years.

$\mathrm{CI}=0.007-0.023, \quad$ WRMR $=0.53), \quad\left(\chi^{2}(16)=23.51, \quad P=0.101\right.$, RMSEA $=0.013, \quad 90 \% \quad C I=0.000-0.024, \quad$ WRMR $=0.44) \quad$ and $\left(\chi^{2}(16)=15.29, P=0.503\right.$, RMSEA $=0.001,90 \% \mathrm{CI}=0.000-0.017$, WRMR $=0.46$ ), for the 10 - and 8-item and 8-item binary versions respectively.

3.5. Validity of the latent factors of depression from four CES-D scale formats in the 65+ age group

Measurement models were again extended to include IADLs, ADLs and perceived stress as exogenous variables (Table 2). Overall, we found that the effects of disability and perceived stress on Depressed Affect, Somatic Affect, Interpersonal and Positive Affect were essentially the same as in the 50+ age group, regardless of the number of items used to represent the factor. There were differences with respect to the impact of age and gender on the Positive Affect factor in the 65+ age group however. Female gender and advancing age were associated with Positive Affect in the 50+ but not the 65+ age group.

\section{Discussion}

This study examined the factor structure of the long and short forms of the CES-D using CFA in a large sample representative of community-living adults aged 50 and over in Ireland. The expected four-factor structure of the 20-item and 10 -item format achieved good model fit in the total cohort aged 50 and over. Both the 8-item binary and frequency response formats also displayed good model fit for the expected three-factor structure. All four versions exhibited good overall internally consistency, with the shorter forms exhibiting almost identical $\alpha$-coefficients. Also, disability and perceived stress had similar associations with the latent factors from the shorter forms as was previously reported for the 20 -item CES-D [26]. Results were very similar in the subset of the cohort aged 65 and over. These results are consistent with previous studies which support the original structure proposed by Radloff $[5,6]$. They strengthen the evidence advocating for the use of the shorter versions of the CES-D in studies of older populations, which help to shorten interview time, diminish response fatigue and eliminate items exhibiting poor psychometric properties [13,27].

We also confirmed the latent factors of depression, i.e. Depressed Affect, Somatic Affect and Positive Affect showed good internally consistency on all formats of the CES-D. However, the reliability coefficients were lower for the Interpersonal Problems factor from the 20- and 10-item versions and for Somatic Affect on the binary 8 -item format in the $56+$ age group. We noted some small fluctuations in the strength of the effects between gender, ADLs and IADLs and the Depressed Affect and Somatic Affect factors on the short formats in the overall cohort and these fluctuations were more apparent in the 65+ age group. This is likely a consequence of the reduction in sample size from the 50+ to 65+ age groups. Despite this, the associations remained significant with consistent direction of effect.

The two-item Positive Affect factor from the short formats was closely representative of the four-item Positive Affect factor from the longer format. Although, the weak associations with age and female gender were not observed in the older age group, the persistence of the negative associations with disability and perceived stress with the four- and two-item Positive Affect factor among the 50+ and 65+ age groups, provides evidence of the validity and reliability of using the two positive items from the short formats to measure Positive Affect in older adults. This 
Table 2

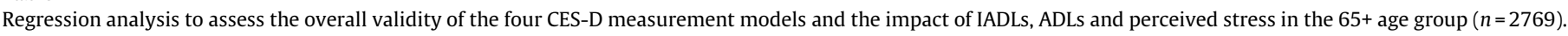

\begin{tabular}{|c|c|c|c|c|}
\hline & Depression & Somatic & Positive Affect & Interpersonal \\
\hline & \multicolumn{4}{|l|}{ 20-item CES-D $(\alpha=0.83)$} \\
\hline $\begin{array}{l}\alpha \\
\text { Age } \\
\text { Sex } \\
\text { IADLs } \\
\text { ADLs } \\
\text { Perceived stress }\end{array}$ & $\begin{array}{l}0.78 \\
-0.007(-0.014-0.000) \\
0.329(0.240-0.419) \\
0.312(0.162-0.462) \\
0.386(0.244-0.528) \\
0.138(0.122-0.154) \\
\chi^{2}(242) 566.41, P<0.00\end{array}$ & $\begin{array}{l}0.71 \\
-0.016(-0.022--0.009) \\
0.267(0.181-0.354) \\
0.576(0.434-0.718) \\
0.561(0.434-0.718) \\
0.138(0.123-0.153) \\
22,90 \% \text { CI: } 0.020-0.024\end{array}$ & $\begin{array}{l}0.61 \\
-0.007(-0.014-0.000) \\
-0.054(-0.138--0.031) \\
-0.179(-0.339--0.018) \\
-0.278(-0.426--0.130) \\
-0.113(-0.127--0.098)\end{array}$ & $\begin{array}{l}0.37 \\
-0.016(-0.027--0.004) \\
0.065(-0.079-0.208) \\
0.277(0.055-0.498) \\
0.128(-0.082-0.338) \\
0.084(0.062-0.106)\end{array}$ \\
\hline $\begin{array}{l}\alpha \\
\text { Age } \\
\text { Sex } \\
\text { IADLs } \\
\text { ADLs } \\
\text { Perceived stress }\end{array}$ & $\begin{array}{l}0.71 \\
0.001(-0.006-0.008) \\
0.310(0.215-0.405) \\
0.210(0.052-0.369) \\
0.398(0.251-0.545) \\
0.135(0.118-0.151) \\
\chi^{2}(58) 143.61, P<0.001 \\
8 \text {-item CES-D }(\alpha=0.76)\end{array}$ & $\begin{array}{l}0.59 \\
-0.011(-0.018--0.004) \\
0.314(0.219-0.408) \\
0.571(0.417-0.726) \\
0.696(0.551-0.840) \\
0.122(0.106-0.138) \\
2390 \% \text { CI: } 0.018-0.028\end{array}$ & $\begin{array}{l}0.63 \\
-0.004(-0.011-0.003) \\
-0.068(-0.158-0.022) \\
-0.171(-0.338--0.005) \\
-0.264(-0.416--0.112) \\
-0.103(-0.118--0.088)\end{array}$ & $\begin{array}{l}0.37 \\
-0.016(-0.027--0.004) \\
0.065(-0.079-0.208) \\
0.277(0.055-0.498) \\
0.127(-0.083-0.337) \\
0.084(0.062-0.106)\end{array}$ \\
\hline $\begin{array}{l}\alpha \\
\text { Age } \\
\text { Sex } \\
\text { IADLs } \\
\text { ADLs } \\
\text { Perceived stress }\end{array}$ & $\begin{array}{l}0.71 \\
0.001(-0.007-0.008) \\
0.310(0.214-0.405) \\
0.211(0.052-0.369) \\
0.399(0.252-0.546) \\
0.135(0.118-0.151) \\
\chi^{2}(41) 118.60, P<0.001 \\
\text { 8-item (binary) CES-D }(c\end{array}$ & $\begin{array}{l}0.59 \\
-0.011(-0.018--0.004) \\
0.313(0.219-0.407) \\
0.573(0.418-0.727) \\
0.695(0.551-0.839) \\
0.122(0.106-0.139) \\
26,90 \% \text { CI: } 0.021-0.032\end{array}$ & $\begin{array}{l}0.63 \\
-0.004(-0.011-0.003) \\
-0.068(-0.158-0.022) \\
-0.171(-0.338--0.005) \\
-0.264(-0.416--0.112) \\
-0.103(-0.118--0.088)\end{array}$ & $\begin{array}{l}\text { NA } \\
\text { NA } \\
\text { NA } \\
\text { NA } \\
\text { NA } \\
\text { NA }\end{array}$ \\
\hline $\begin{array}{l}\alpha \\
\text { Age } \\
\text { Sex } \\
\text { IADLs } \\
\text { ADLs } \\
\text { Perceived stress }\end{array}$ & $\begin{array}{l}0.60 \\
0.000(-0.010-0.011) \\
0.198(0.065-0.331) \\
0.239(0.030-0.448) \\
0.472(0.283-0.661) \\
0.142(0.119-0.165) \\
\chi^{2}(41) 68.97, P=0.040 .\end{array}$ & $\begin{array}{l}0.47 \\
-0.023(-0.032--0.013) \\
0.203(0.078-0.328) \\
0.795(0.606-0.984) \\
0.622(0.446-0.798) \\
0.106(0.085-0.127) \\
90 \% \text { CI: } 0.009-0.022\end{array}$ & $\begin{array}{l}0.58 \\
-0.006(-0.015-0.002) \\
-0.027(-0.138-0.085) \\
-0.225(-0.413--0.037) \\
-0.220(-0.395--0.044) \\
-0.090(-0.108-0.072)\end{array}$ & $\begin{array}{l}\text { NA } \\
\text { NA } \\
\text { NA } \\
\text { NA } \\
\text { NA } \\
\text { NA }\end{array}$ \\
\hline
\end{tabular}

Values reported are regression coefficients $(\beta)$ with 95\% confidence intervals (95\% CI); $\alpha$ : Cronbach's alpha coefficient.

reflects previous reports for the four-item Positive Affect factor [18-20]. This disability and perceived stress are highly correlated with other important physical (falls, frailty and mortality) and psychological (anxiety and loneliness) outcomes [28,29]. Thus, investigating the relationships between these outcomes and Positive Affect from the shorter forms of the CES-D has validity.

A strength of this study is the large representative sample which allows robust CFA analyses to be performed. It provides support for the use of shorter forms of the CES-D to measure depressive symptoms and Positive Affect in similar populations. Although, it is important to note that this study focuses only on the factor structure and validity of the CES-D and its latent factors. The sensitivity and specificity of the long and short forms to detect clinically relevant depression is beyond the score of this study. The limitations of this study are mainly concerned with issues of measurement. We used one administration of the 20-item CES-D as the basis of our analysis. This may have introduced measurement bias associated with the ordering of the items, which would differ if separate 10- and 8-item versions had been administered. However, repeated administrations of the CES-D to the same participants would introduce measurement bias due to the problem of response fatigue in older adults. Finally, we acknowledge the limitations of the cross-sectional design of the study. Subsequent waves of the TIILDA study will help to further test the data presented here.

This study shows that the factor structure of depression from the shorter forms of the CES-D displays good internal consistency, reliability and validity compared with the long form in the community-living adult population aged $50+$ and $65+$ years. We also confirm validity of using short forms of the scale to measure Positive Affect, a construct of growing importance to beneficial health outcomes, physical resilience and psychological well-being in later life. Clinicians working in the field of geriatric medicine most often administer the CES-D as part of a comprehensive geriatric assessment. Therefore, using a short version of the CES-D is supported, and may even be preferable in the general population of older adults, where avoiding long assessments and response fatigue is warranted.

\section{Disclosure of interest}

The authors declare that they have no conflicts of interest concerning this article.

\section{Acknowledgements}

The authors would like to acknowledge the contribution of the participants in the study, members of the TILDA research team, study nurses, and administrators. Funding was gratefully received from the Atlantic Philanthropies, the Irish Government Department of Health and Children, and Irish Life plc.

\section{Appendix A. Supplementary data}

Supplementary data (Appendices 1 and 2) associated with this article can be found, in the online version, at http://dx.doi.org/ 10.1016/j.eurger.2013.12.004. 
EURGER-452; No. of Pages 6

6

A.M. O'Halloran et al./European Geriatric Medicine $x x x$ (2014) $x x x-x x x$

References

[1] Beekman AT, Penninx BW, Beg DJ, de Burs E, Geerling SW, van Tilburg W. The impact of depression on the well-being, disability and use of services in older adults: a longitudinal perspective. Act Psychiatr Stand 2002;105(1):207 [Epub 2002/06/28].

[2] Kessler RC, Birnbaum H, Bromet E, Huang I, Sampson N, Shahly V. Age differences in major depression: results from the National Comorbidity Survey Replication (NCS-R). Psychol Med 2010;40(2):225-37 [Epub 2009/06/18].

[3] Lewinsohn PM, Seeley JR, Roberts RE, Allen NB. Center for Epidemiologic Studies Depression Scale (CES-D) as a screening instrument for depression among community-residing older adults. Psychol Aging 1997;12(2):277-87 [Epub 1997/06/01].

[4] Radloff LS. The CES-D scale: a self-report depression scale for research in the general population. Apple Psychol Meas 1977;1:385-401.

[5] Chafer AB. Meta-analysis of the factor structures of four depression questionnaires: Beck, CES-D, Hamilton, and Zing. J Chin Psychol 2006;62(1):123-46 [Epub 2005/11/16].

[6] Chang B, Fokkema M, Cuijpers P, Li J, Sits N, Beekman A. Measurement invariance of the Center for Epidemiological Studies Depression Scale (CES-D) among Chinese and Dutch elderly. BMC Med Res Methodol 2011;11:74 [Epub 2011/05/21].

[7] Guarnaccia PJ, Angel R, Worobey JL. The factor structure of the CES-D in the Hispanic Health and Nutrition Examination Survey: the influences of ethnicity, gender and language. Soc Sci Med 1989;29(1):85-94 [Epub 1989/01/01].

[8] Thomas JL, Brantley PJ. Factor structure of the Center for Epidemiological Studies-Depression Scale in low-income women attending primary care clinics. Eur J Psychol Assess 2004;20(2):106-15.

[9] Schroevers MJ, Sanderman R, van Sonderen E, Rancher AV. The evaluation of the Center for Epidemiologic Studies Depression (CES-D) scale: Depressed and Positive Affect in cancer patients and healthy reference subjects. Qual Life Res 2000;9(9):1015-29 [Epub 2001/05/03].

[10] Ostir GV, Markides KS, Black SA, Goodwin JS. Emotional well-being predicts subsequent functional independence and survival. J Am Geriatr Soc 2000;48(5):473-8 [Epub 2000/05/16].

[11] Olson TR, Presniak MD, MacGregor MW. Reevaluating positive affect in the Center for Epidemiologic Studies-Depression scale. Psychiatry Res 2010;178(3):545-9 [Epub 2010/06/12].

[12] Andresen EM, Malmgren JA, Carter WB, Patrick DL. Screening for depression in well older adults: evaluation of a short form of the CES-D (Center for Eidemiologic Studies Depression Scale). Am J Prev Med 1994;10(2):77-84 [Epub 1994/03/01].

[13] Kohout FJ, Berkman LF, Evans DA, Cornoni-Huntley J. Two shorter forms of the CES-D (Center for Epidemiological Studies Depression) depression symptoms index. J Aging Health 1993;5(2):179-93 [Epub 1993/04/08].
[14] Wallace RB, Herzog AR, Ofstedal MB, Steffick DE, Fonda S, Langa K. Documentalion of affective functioning measures in the health and retirement study. Ann Arbor, MI: Survey Research Center. University of Michigan; 2000.

[15] Van de Veld S, Bracke P, Levecque K. Gender differences in depression in 23 European countries. Cross-national variation in the gender gap in depression. Soc Sci Med 2010;71(2):305-13 [Epub 2010/05/21].

[16] Chen ST, Chan AC, Fund HH. Factorial structure of a short version of the Center for Epidemiologic Studies Depression Scale. Int J Geriatr Psychiatry 2006;21(4):333-6 [Epub 2006/03/30].

[17] Lee AE, Chokkanathan S. Factor structure of the 10-item CES-D scale among community-dwelling older adults in Singapore. Int J Geriatr Psychiatry 2008;23(6):592-7 [Epub 2007/11/21].

[18] Kurland BF, Gill TM, Patrick DL, Larson EB, Phelan EA. Longitudinal change in positive affect in community-dwelling older persons. J Am Geriatr Soc 2006;54(12):1846-53 [Epub 2007/01/03].

[19] Ostir GV, Goodwin JS, Markides KS, Ottenbacher KJ, Balfour J, Guralnik JM. Differential effects of premorbid physical and emotional health on recovery from acute events. J Am Geriatr Soc 2002;50(4):713-8 [Epub 2002/05/02].

[20] Folkman S. The case for positive emotions in the stress process. Anxiety Stress Coping 2008;21(1):3-14 [Epub 2007/11/21].

[21] Kearney PM, Cronin H, O’Regan C, Kamiya Y, Suva GM, Whelan B, et al. Cohort profile: the Irish Longitudinal Study on ageing. Int $\mathrm{J}$ Epidemiol 2011;40(4):877-84 [Epub 2011/08/04].

[22] Cohen S, Williamson G. Perceived stress in a probability sample of the United States. In: Spacapan S, Oskamp S, editors. The social psychology of health. Newburg Park, CA: Sage; 1988.

[23] Browne MW, Cudeck R. Alternative ways of assessing model fit. Sociol Methods Res 1992;21:230-58.

[24] King-Kallimanis BL, Oort FJ, Tishelman C, Strangers MAG. Comparison of procedures used to test measurement invariance in longitudinal factor analysis. Netherlands J Psychol Health 2012;67(3):91-100.

[25] Kaplan D. Evaluating and modifying covariance structure model models - a review and recommendation. Multivariate Behav Res 1990;25:137-55.

[26] Barry LC, Murphy TE, Gill TM. Depressive symptoms and functional transitions over time in older persons. Am J Geriatr Psychiatry 2011;19(9):783-91 [Epub 2011/08/30].

[27] Long Foley K, Reed PS, Mutran EJ, DeVellis RF. Measurement adequacy of the CES-D among a sample of older African-Americans. Psychiatry Res 2002;109(1):61-9 [Epub 2002/02/19].

[28] Fried LP, Tangen CM, Walston J, Newman AB, Kirsch C, Gottdiener J, et al. Frailty in older adults: evidence for a phenotype. J Gerontol A Biol Sci Med Sci 2001;56(3):M146-56 [Epub 2001/03/17].

[29] Shiovitz-Ezra S, Leitsch S, Graben J, Karraker A. Quality of life and psychological health indicators in the national social life, health, and aging project. J Gerontol B Psychol Sci Soc Sci 2009;64(Suppl. 1):i30-7 [Epub 2009/02/11].

Please cite this article in press as: O'Halloran AM, et al. The latent factors of depression from the short forms of the CES-D are consistent, reliable and valid in community-living older adults. Eur Geriatr Med (2014), http://dx.doi.org/10.1016/j.eurger.2013.12.004 